\title{
Efeito de parâmetros hidrolíticos na obtenção de hidrolisados proteicos de farinha de trigo com baixo teor de fenilalanina
}

\author{
Effect of hydrolytic parameters in obtaining of protein hydrolysates of wheat flour with low phenylalanine content
}

\author{
Raquel Linhares CARREIRA ${ }^{1}$; Camila Salles RAMOS ${ }^{1}$; André Belico de VASCONCELOS ${ }^{2}$; \\ Marcelo Matos SANTORO²; Marialice Pinto Coelho SILVESTRE ${ }^{1 *}$
}

\begin{abstract}
Resumo
Tendo como objetivo a obtenção de hidrolisados proteicos de farinha de trigo com baixo teor de fenilalanina (Phe), foram preparados, inicialmente, extratos proteicos da farinha de trigo, empregando-se método enzimático pela ação de protease de Bacillus licheniformis. Em seguida, esses extratos foram hidrolisados sob a ação do extrato enzimático bruto (EEB), obtido de casca de abacaxi, e de pancreatina comercial; e alguns parâmetros hidrolíticos foram avaliados, tais como temperatura $\left(30 ; 35 ; 40\right.$; 50 ; e $\left.70{ }^{\circ} \mathrm{C}\right)$, tempo ( 1 hora e 30 minutos; 2 horas e 30 minutos; 3 horas e 30 minutos), e pH de reação $(6,0 ; 7,0 ; 8,0$ e 9,0). Para a remoção de Phe, empregou-se o carvão ativado (CA) e a eficiência deste processo foi avaliada determinando-se o teor de Phe por espectrofotometria derivada segunda, na farinha de trigo, assim como nos hidrolisados após tratamento com CA. Para os três parâmetros estudados, observaram-se efeitos variados sobre a remoção de Phe, sendo que os melhores resultados foram encontrados ao se empregar a associação sucessiva de EEB (E:S 10:100, 1 hora e 30 minutos), com a pancreatina (E:S 4:100, 3 horas e 30 minutos), em pH 7,0 a $50{ }^{\circ} \mathrm{C}$, tendo atingido $66,28 \%$ de remoção de Phe, o que corresponde a um teor final de Phe de 522,44 mg.100 g ${ }^{-1}$ de hidrolisado.
\end{abstract}

Palavras-chave: farinha de trigo; extração proteica; hidrólise; enzimas; fenilalanina.

\begin{abstract}
With the aim of obtaining wheat flour hydrolysates with low-phenylalanine (Phe) content, protein extracts were prepared using an enzymatic method through the action of a protease from Bacillus licheniformis. Next, these protein extracts were hydrolyzed by a crude enzymatic extract (CEE) obtained from pineapple peel followed by a commercial enzyme (pancreatin). Some parameters, such as temperature (30, 35, 40,50 and $70{ }^{\circ} \mathrm{C}$ ), time ( 1 hour and 30 minutes, 2 hours and 30 minutes, 3 hours and 30 minutes), and $\mathrm{pH}$ of the reaction (6.0, 7.0, 8.0 and 9.0) were evaluated. Activated carbon (AC) was used for removing Phe and the efficiency of this process was evaluated by second derivative spectrophotometry, measuring Phe content in wheat flour as well as in its hydrolysates after AC treatment. Varied effects were observed for the three parameters studied, and the best results were found using successive association of CEE (E: S 10:100, 1 hour and 30 minutes) with

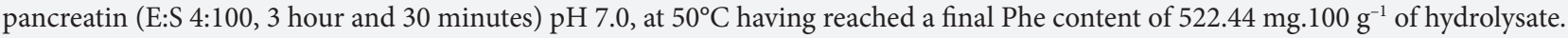

Keywords: wheat flour; protein extraction; hydrolysis, enzymes; phenylalanine; removal.
\end{abstract}

\section{Introdução}

A fenilcetonúria ou PKU, como é mundialmente conhecida, é uma doença genética, causada por mutação no gene que codifica a enzima fenilalanina-hidroxilase, ativa no fígado e responsável pela transformação do aminoácido fenilalanina (Phe) em tirosina. A elevação de Phe no sangue, acima de $10 \mathrm{mg} \cdot \mathrm{dL}^{-1}$, permite a passagem em quantidade excessiva para o Sistema Nervoso Central, e o acúmulo tem efeito tóxico, causando o retardo mental, que é a mais importante sequela dessa doença (MONTEIRO; CANDIDO, 2006).

O tratamento é dietético, consistindo na exclusão ou substituição de todos os alimentos fornecedores de fenilalanina. Com este controle dietético, a deficiência mental deixará de ocorrer, justificando assim a necessidade de se produzir e disponibilizar alimentos adequados (MONTEIRO; CANDIDO,
2006). No Brasil, são utilizadas misturas de aminoácidos livres, importadas e de elevado custo. Estes fatores, associados à baixa disponibilidade de alimentos com teores reduzidos de Phe, torna a dieta de fenilcetonúricos monótona, pouco atrativa e de difícil adesão (MIRA; MARQUEZ, 2000).

Dentre os alimentos de maior consumo no Brasil, encontrase a farinha de trigo, com ampla utilização no preparo de produtos industriais e caseiros. Entretanto, este alimento apresenta teor de Phe acima do permitido para fenilcetonúricos (NUPAD, 2002), restringindo, dessa forma, sua incorporação na dieta desses pacientes. Uma alternativa viável a esta restrição dietética seria o desenvolvimento de farinha de trigo com baixo teor de Phe, a ser empregada na alimentação de crianças e adultos portadores desta enfermidade. 
A primeira etapa no desenvolvimento desta farinha de trigo envolve a extração proteica que pode ser feita enzimaticamente, como descrito anteriormente pelo grupo do Laboratório de Bromatologia/Pesquisa da UFMG, onde se realizou o presente trabalho (CAPOBIANGO et al., 2007). Em seguida, fazse a hidrólise proteica, empregando-se diferentes enzimas proteolíticas e condições de reação (CAPOBIANGO et al., 2006). No preparo de hidrolisados proteicos, utilizam-se normalmente proteases comerciais, que são produtos caros e normalmente importados. Por esta razão, neste trabalho, testou-se a associação de enzima comercial com extrato enzimático preparado no citado laboratório, visando à redução dos custos do processo. A etapa seguinte compreende a remoção de Phe empregando-se alguns métodos tais como filtração em gel, adsorção por carvão ativado ou resinas (DE HOLANDA; VASCONCELOS et al., 1989; LOPES; DELVIVO; SILVESTRE, 2005; DELVIVO et al., 2006; SOARES et al., 2006; BIZZOTTO et al., 2006a,b) por um meio adsorvente (LOPEZ-BAJONERO et al., 1991; OUTINEN et al., 1996; SHIMAMURA et al., 1999).

A espectrofotometria derivada segunda (EDS) tem sido empregada por vários autores para quantificar resíduos de Phe em proteínas, mostrando ser uma técnica rápida, útil e confiável (BRANDTS; KAPLAN, 1973; O'HAVER, 1979; MATSUSHIMA; INOUE; SHIBATA, 1975; ICHIKAWA; TERADA, 1977, 1979, 1981a,b; CAHILL; PADERA, 1980). No mesmo laboratório do presente trabalho, esta técnica já foi utilizada com êxito na determinação da taxa de encapsulamento de hidrolisados proteicos (SILVESTRE; DAUPHIN; HAMON, 1993; MORAIS et al., 2002) e na avaliação da porcentagem de remoção de Phe, pelo carvão ativado, de hidrolisados enzimáticos de leite em pó desnatado (SOARES et al., 2004; LOPES; DELVIVO; SILVESTRE, 2005), soro de leite (DELVIVO et al., 2006), arroz (BIZZOTTO et al., 2006a,b), fubá (CAPOBIANGO et al., 2006) e farinha de arroz (VIEIRA et al., 2008). Neste estudo, esta técnica foi empregada para se avaliar a eficiência da remoção de Phe de hidrolisados proteicos obtidos a partir da farinha de trigo.

Este trabalho envolveu o estudo do efeito de alguns parâmetros empregados na hidrólise das proteínas extraídas da farinha de trigo, sobre a remoção de Phe, empregando-se o carvão ativado (CA) como meio adsorvente.

\section{Material e métodos}

\subsection{Material}

A farinha de trigo (classificada como farinha especial, conforme BRASIL, 1996, ou como tipo I segundo BRASIL, 2005) foi adquirida no comércio de Belo Horizonte, MG. A protease Protemax 580 L (EC 3.4.21.14, uma serino-endopeptidase de origem bacteriana - cepa do Bacillus licheniformis -, atividade 580 KDU.g-1 ${ }^{-1}$ estável em pH entre 7 e 10, com pH ótimo em 9,5 , temperatura ótima de $60^{\circ} \mathrm{C}$ e temperatura de inativação acima de $85^{\circ} \mathrm{C}$ por 10 minutos) foi adquirida da Prozyn (São Paulo, SP, Brasil). A pancreatina Corolase PP (EC 3.4.21.4, complexo enzimático obtido do pâncreas constituído pelas serina-endopeptidases tripsina e quimotripsina, e pelas metalo-exopeptidases carboxipeptidases A e B, atividade
200.000 LVE.g ${ }^{-1}$, pH ótimo de 9 e temperatura ótima de $50{ }^{\circ} \mathrm{C}$ ) foi adquirida da $\mathrm{AB}$ Enzymes Brasil Comercial Ltda. (Barueri, SP, Brasil). Os aminoácidos L-fenilalanina, L-tirosina e L-triptofano foram adquiridos da Sigma-Aldrich (St. Louis, MO, EUA). O carvão ativado (granulado $\mathrm{n}^{\circ} 119,20 \times 50$ mesh, $12 \times 25$ mesh, $6 \times 12$ mesh) foi adquirido da Carbomafra S. A. (Curitiba, PR, Brasil). O extrato enzimático bruto (EEB) da casca do abacaxi (Ananás comosus) variedade Pérola, foi preparado no laboratório. Utilizou-se Liofilizador Freezone (modelo 77500, Labconco, Kansas City, MI, EUA), compressor (Diapump, Fanem, mod. 089-A, série BE11778, São Paulo, SP, Brasil), e cutter (Sire, modelo Super Cutter, São Paulo, SP, Brasil). Os demais reagentes foram de grau analítico.

\subsection{Métodos}

\section{Extração das proteínas}

Empregou-se método de extração enzimática das proteínas da farinha de trigo, utilizando-se o procedimento descrito pelo Laboratório de Bromatologia/Pesquisa da Faculdade de Farmácia da UFMG (CAPOBIANGO et al., 2007).

$\mathrm{O}$ pH de uma suspensão aquosa da farinha de trigo foi ajustado para 9,5 e a temperatura, ajustada para $40{ }^{\circ} \mathrm{C}$, a ela adicionou-se a protease de Bacillus licheniformis (E:S 10:100) e foi agitada por 2 horas. $\mathrm{O}$ extrato proteico da farinha de trigo (EPFT) foi separado do resíduo por centrifugação a $25^{\circ} \mathrm{C}$, por 15 minutos, a $1700 \times \mathrm{g}$. O rendimento da extração proteica (REP) foi calculado indiretamente (Equação 1), determinandose o teor de proteínas do resíduo pelo Método Kjedahl 2.0.49 (AOAC, 1995) após sua secagem em estufa com circulação de ar a $65^{\circ} \mathrm{C}$.

$\mathrm{REP}=\frac{[(\mathrm{A} \times \mathrm{B})-(\mathrm{C} \times \mathrm{D})]}{(\mathrm{A} \times \mathrm{B})} \times 100$

em que, REP = rendimento de extração proteica (\%); $\mathrm{A}=$ Teor de proteína na farinha de trigo (g.100 $\mathrm{g}^{-1} \mathrm{ou} \%$ ); $\mathrm{B}=$ Quantidade de farinha de trigo especial utilizada na extração (g); C = Peso de resíduo obtido na extração $(\mathrm{g})$; e $\mathrm{D}$ = Teor de proteína no resíduo (g. $100 \mathrm{~g}^{-1}$ ou \%).

\section{Preparo e caracterização do extrato} enzimático bruto da casca de abacaxi

Para o preparo do extrato enzimático bruto da casca de abacaxi (EEB), as amostras foram, inicialmente, lavadas, descascadas e as porções de casca foram processadas em cutter e filtradas em gaze. Posteriormente, foram centrifugadas a $6000 \times \mathrm{g}$ por 15 minutos, a $4{ }^{\circ} \mathrm{C}$. Ao sobrenadante foram adicionados $10 \mathrm{~mL}$ de uma solução contendo EDTA $\left(4,0 \times 10^{-3} \mathrm{~mol} \cdot \mathrm{L}^{-1}\right) \mathrm{e}$ cisteína $\left(10^{-2} \mathrm{~mol} . \mathrm{L}^{-1}\right)$, sendo, em seguida, congelado.

A caracterização do EEB abrangeu as determinações dos valores ótimos de $\mathrm{pH}$, temperatura e tempo, as quais foram feitas de acordo com a metodologia descrita por Tremacoldi e Carmona (2005) com algumas modificações relacionadas ao substrato (uso de hemoglobina ao invés de caseína) e ao 
tampão empregados (utilização de tampão fosfato ao invés de tampão TRIS).

\section{Preparo dos hidrolisados proteicos}

Foram preparados nove hidrolisados enzimáticos, empregando-se o EEB na relação enzima:substrato (E:S) 10:100, em associação sucessiva com a pancreatina (E:S 4:100), tendo sido variados os seguintes parâmetros: temperatura $(35,40$, 50 e $70^{\circ} \mathrm{C}$ ), tempo de hidrólise ( 1 hora e 30 minutos, 2 horas e 30 minutos e 3 horas e 30 minutos) e $\mathrm{pH}(6,0 ; 7,0 ; 8,0$ e 9,0) (Tabela 1).

Inicialmente, $50 \mathrm{~mL}$ do EPFT foram colocados em quatro erlenmeyers e o $\mathrm{pH}$ foi ajustado com solução de $\mathrm{NaOH}$ a 3 mol.L $\mathrm{L}^{-1}$ ou de $\mathrm{HCl}$ 0,1 mol.L $\mathrm{L}^{-1}$, para os valores de pH 6,0; 7,0; 8,0 e 9,0. Após o ajuste do $\mathrm{pH}$, o EPFT foi levado ao banho de vaselina líquida sobre agitador magnético, com agitação constante, variandose os valores de temperatura para $35,40,50$ e $70{ }^{\circ} \mathrm{C}$. Após a estabilização da temperatura, adicionou-se o EEB e, em seguida, a pancreatina, variando-se o tempo de ação destes em 1 hora e 30 minutos/3 horas e 30 minutos; 2 horas e 30 minutos/2 horas e 30 minutos e 3 horas e 30 minutos/1 hora e 30 minutos, respectivamente, totalizando 5 horas de reação. Finalmente, a reação hidrolítica foi interrompida por aquecimento em banhomaria a $90^{\circ} \mathrm{C}$, por 20 minutos, e os hidrolisados foram submetidos ao processo de liofilização, sendo que seus teores de Phe (LOPES; DELVIVO; SILVESTRE, 2005) e de proteína (AOAC, 1995) foram determinados por espectrofotometria derivada segunda e microkjeldahl, respectivamente.

\section{Remoção de fenilalanina dos hidrolisados proteicos}

A Phe foi removida dos hidrolisados proteicos de farinha de trigo pela utilização do CA, como meio adsorvente, usando a

Tabela 1. Parâmetros empregados no preparo dos hidrolisados protéicos da farinha de trigo.

\begin{tabular}{|c|c|c|c|c|}
\hline Hidrolisado & Proteases & $\begin{array}{c}\text { Temperatura } \\
\left({ }^{\circ} \mathrm{C}\right)\end{array}$ & $\begin{array}{l}\text { Tempo de hidrólise } \\
\text { EEB/ pancreatina } \\
\text { (horas) }\end{array}$ & $\mathrm{pH}$ \\
\hline 01 & $\begin{array}{c}\text { EEB }+ \\
\text { pancreatina }\end{array}$ & 35 & $\begin{array}{l}1 \text { hora e } 30 \text { minutos/ } \\
3 \text { horas e } 30 \text { minutos }\end{array}$ & 7,0 \\
\hline 02 & $\begin{array}{c}\mathrm{EEB}+ \\
\text { pancreatina }\end{array}$ & 40 & $\begin{array}{l}1 \text { hora e } 30 \text { minutos/ } \\
3 \text { horas e } 30 \text { minutos }\end{array}$ & 7,0 \\
\hline 03 & $\begin{array}{c}\mathrm{EEB}+ \\
\text { pancreatina }\end{array}$ & 50 & $\begin{array}{l}1 \text { hora e } 30 \text { minutos/ } \\
3 \text { horas e } 30 \text { minutos }\end{array}$ & 7,0 \\
\hline 04 & $\begin{array}{c}\text { EEB }+ \\
\text { pancreatina }\end{array}$ & 70 & $\begin{array}{l}1 \text { hora e } 30 \text { minutos/ } \\
3 \text { horas e } 30 \text { minutos }\end{array}$ & 7,0 \\
\hline 05 & $\begin{array}{c}\text { EEB }+ \\
\text { pancreatina }\end{array}$ & 50 & $\begin{array}{l}2 \text { hora e } 30 \text { minutos/ } \\
2 \text { horas e } 30 \text { minutos }\end{array}$ & 7,0 \\
\hline 06 & $\begin{array}{c}\mathrm{EEB}+ \\
\text { pancreatina }\end{array}$ & 50 & $\begin{array}{c}3 \text { horas e } 30 \text { minutos/ } \\
1 \text { hora e } 30 \text { minutos }\end{array}$ & 7,0 \\
\hline 07 & $\begin{array}{c}\text { EEB + } \\
\text { pancreatina }\end{array}$ & 50 & $\begin{array}{l}1 \text { hora e } 30 \text { minutos/ } \\
3 \text { horas e } 30 \text { minutos }\end{array}$ & 6,0 \\
\hline 08 & $\begin{array}{c}\mathrm{EEB}+ \\
\text { pancreatina }\end{array}$ & 50 & $\begin{array}{l}1 \text { hora e } 30 \text { minutos/ } \\
3 \text { horas e } 30 \text { minutos }\end{array}$ & 8,0 \\
\hline 09 & $\begin{array}{c}\text { EEB + } \\
\text { pancreatina }\end{array}$ & 50 & $\begin{array}{l}1 \text { hora e } 30 \text { minutos/ } \\
3 \text { horas e } 30 \text { minutos }\end{array}$ & 9,0 \\
\hline
\end{tabular}

$\mathrm{E}: \mathrm{S}$ = Relação enzima:substrato; EEB: extrato bruto da casca de abacaxi. relação proteína:carvão ativado de 1:88,5 (CAPOBIANGO et al., 2006; VIEIRA et al., 2008).

Foi empregado o procedimento de passagem por coluna, descrito por SOARES et al. (2004). Dois gramas de CA de granulometrias diferentes (granulado $\mathrm{n}^{\circ} 119,20 \times 50$ mesh, $12 \times 25$ mesh, $6 \times 12$ mesh série Tyler) foram hidratados com água destilada por 10 minutos sob agitação constante e, em seguida, colocados em seringa descartável de $10 \mathrm{~mL}$ contendo filtro de nylon com lã de vidro. Em seguida, os hidrolisados foram passados pela coluna e submetidos à pressão, tendo sido recolhidos os eluatos.

A avaliação da eficiência de remoção de Phe pelo CA foi realizada pela medida do teor de Phe livre, na farinha de trigo e em seus hidrolisados, após tratamento com CA, empregando-se a espectrofotometria derivada segunda, como descrita por Lopes, Delvivo e Silvestre, 2005.

A eficiência da remoção de Phe foi calculada de acordo com a Equação 2:

$\%$ Remoção de Phe $=\frac{[\mathrm{A}-(\mathrm{B} \times \mathrm{C} / \mathrm{D})]}{\mathrm{A}} \times 100$

em que: $\mathrm{A}=$ Teor de Phe na farinha de trigo ( $\mathrm{mg}$ Phe. $100 \mathrm{~g}^{-1}$ ); $\mathrm{B}=$ Teor de Phe no hidrolisado proteico, após tratamento com CA (mg Phe. $100 \mathrm{~g}^{-1}$ ); $\mathrm{C}=$ Teor de proteína na farinha de trigo (g.100 g ou \%); e D = Teor de proteína no hidrolisado proteico $\left(\mathrm{g} .100 \mathrm{~g}^{-1}\right)$.

\section{Análise estatística}

Todos os experimentos foram feitos em três repetições, no mesmo dia, e as análises foram realizadas em triplicata. Utilizaram-se a Análise de Variância (ANOVA fator único) e o Teste de Duncan a 5\% de probabilidade para comparar entre si os teores finais de Phe nos hidrolisados após tratamento com CA. A curva padrão foi obtida por análise de regressão (PIMENTEL-GOMES, 2000).

\section{Resultados e discussão}

\subsection{Parâmetros hidrolíticos}

Os valores ótimos de $\mathrm{pH}$, temperatura e tempo, correspondentes aos valores máximos de atividade específica para o extrato enzimático bruto da casca de abacaxi foram de $\mathrm{pH}=6,0 ; 70{ }^{\circ} \mathrm{C}$ e 1 hora e 30 minutos. Além disso, os valores mais elevados de atividade específica foram encontrados na faixa de $\mathrm{pH} 5,0$ a 7,0. Para a pancreatina comercial, a faixa de maior atividade específica foi de pH 7,0 a 9,0 (AB ENZYMES, 2001).

\subsection{Eficiência da remoção de fenilalanina}

$\mathrm{Na}$ Tabela 2 estão apresentados os resultados obtidos para a remoção de Phe dos diferentes hidrolisados proteicos da farinha de trigo. $\mathrm{O}$ teor de Phe na farinha de trigo foi de $354 \mathrm{mg}$ Phe. $100 \mathrm{~g}^{-1}$ (com 8,57\% de proteína). 
Tabela 2. Percentual de remoção e teor final de fenilalanina dos hidrolisados protéicos de farinha de trigo.

\begin{tabular}{ccc}
\hline Hidrolisados & $\begin{array}{c}\text { Remoção de Phe } \\
(\%)\end{array}$ & $\begin{array}{c}\text { Teor final de Phe } \\
\left(\mathrm{mg} \text { Phe. } 100 \mathrm{~g}^{-1} \text { de HPFT }\right)^{1}\end{array}$ \\
\hline 1 & $61,53^{\mathrm{b}}$ & $598,21^{\mathrm{h}}$ \\
2 & $57,49^{\mathrm{c}}$ & $661,03^{\mathrm{g}}$ \\
3 & $66,28^{\mathrm{a}}$ & $522,44^{\mathrm{i}}$ \\
4 & $56,93^{\mathrm{c}}$ & $669,74^{\mathrm{f}, \mathrm{g}}$ \\
5 & $42,26^{\mathrm{e}}$ & $897,93^{\mathrm{c}, \mathrm{d}}$ \\
6 & $38,76^{\mathrm{g}, \mathrm{h}}$ & $952,41^{\mathrm{a}, \mathrm{b}}$ \\
7 & $39,90^{\mathrm{fg}}$ & $934,58^{\mathrm{b}, \mathrm{c}}$ \\
8 & $46,09^{\mathrm{d}}$ & $838,37^{\mathrm{e}}$ \\
9 & $37,41^{\mathrm{g}, \mathrm{h}}$ & $973,41^{\mathrm{a}, \mathrm{b}}$ \\
\hline
\end{tabular}

HPFT $=$ Hidrolisado protéico de farinha de trigo. ${ }^{1}$ Teor de Phe nos hidrolisados. Os resultados representam médias das repetições. Médias indicadas por letras iguais, na mesma coluna, não diferem entre si a $5 \%$ de probabilidade pelo teste de Duncan.

Como pode ser observado nesta tabela, obtiveram-se percentuais de remoção de Phe que variaram de 37,41 a 66,28\%, e o teor final de Phe de 522,44 a 973,41 mg Phe.100 g-1 de hidrolisado.

Embora a taxa de remoção de Phe dos hidrolisados proteicos de farinha de trigo não tenha sido elevada, deve-se considerar que novos estudos serão realizados a partir deste hidrolisado obtido, adicionando-o ao resíduo (amido) que foi separado no início da extração proteica, visando ao desenvolvimento de uma farinha de trigo com baixo teor de Phe. Sendo assim, embora todos os hidrolisados tenham apresentado elevado teor final de Phe, este poderá ser reduzido, de maneira a ajustá-lo ao limite permitido pela legislação brasileira (BRASIL, 2002) para produtos para PKU (0,1 g.100 g $\left.\mathrm{g}^{-1}\right)$.

A dificuldade de se remover Phe da farinha de trigo poderia estar associada, pelo menos em parte, à complexidade estrutural das gluteninas, assim como ao tratamento térmico pelo qual passam estas proteínas durante o processo de remoção $\left(50{ }^{\circ} \mathrm{C}\right.$ por 5 horas). Assim, segundo Macritchie e Lafiandra (1997), a ação do calor é capaz de transformar subunidades poliméricas de gluteninas do trigo em grandes polímeros. Nesta forma, o acesso da enzima ficaria prejudicado, o que levaria a uma menor exposição ou liberação de Phe e, consequentemente, a uma remoção inferior deste aminoácido.

Deve-se ressaltar que a presença de certa quantidade de Phe no produto final para fenilcetonúricos é desejável do ponto de vista nutricional, uma vez que, por ser um aminoácido essencial, a Phe é fundamental para o crescimento normal de crianças. Além disso, as condições operacionais necessárias para atingir cerca de $100 \%$ de remoção de Phe, aumentariam demasiadamente os custos do processo (SOARES et al., 2006; LOPES et al., 2007).

Não foram encontrados na literatura dados sobre a remoção de Phe da farinha de trigo. Entretanto, existem estudos realizados no mesmo laboratório empregando-se outras fontes proteicas, tais como leite (SOARES et al., 2006; LOPES et al., 2007), soro de leite (DE MARCO et al., 2005; DELVIVO et al., 2006; SILVA et al., 2005), arroz em grãos (BIZZOTTO et al., 2006a,b), fubá de milho (CAPOBIANGO et al., 2006) e farinha de arroz (VIEIRA et al., 2008), nos quais foram alcançados valores de remoção de Phe acima de $90 \%$, superiores aos obtidos neste trabalho.

Outros autores relataram níveis de remoção de Phe superiores aos obtidos neste trabalho. Assim, Lopez-Bajonero et al. (1991) removeram $92 \%$ de Phe de hidrolisados proteicos de leite em pó desnatado e caseinato de sódio obtidos pela ação de protease do Aspergillus oryzae (Enzimas y Productos Quimicos S.A.) seguida da papaína (Hervi S.A.), tratados com CA. Empregando um sistema de três enzimas (quimotripsina, carboxipeptidase A e leucina aminopeptidase, Sigma-Aldrich), Moszczynski e Idziak (1993) removeram, através do CA, 89,5\% de Phe de hidrolisados de caseína. Por outro lado, Cogan, Moshe e Mokady (1981) alcançaram remoção de Phe de 36\%, em hidrolisados de caseína preparados pela ação da enzima Rhozima 62 (Rhom e Hass), valor este que está próximo dos obtidos para algumas amostras do presente trabalho.

\subsection{Efeito de alguns parâmetros hidroliticos sobre a remoção de fenilalanina}

$p H$

Para se avaliar o efeito do $\mathrm{pH}$, pode-se comparar os resultados obtidos para os hidrolisados 3 ( $\mathrm{pH} \mathrm{7,0),} 7$ ( $\mathrm{pH} \mathrm{6,0),}$ $8(\mathrm{pH} 8,0)$ e 9 ( $\mathrm{pH} 9,0)$. Observa-se na Tabela 2 que o $\mathrm{pH}$ 7,0 (combinado com $50{ }^{\circ} \mathrm{C}$ e tempo de hidrólise EEB 1 hora e 30 minutos/pancreatina 3 horas e 30 minutos) foi o mais favorável, uma vez que levou à maior remoção de Phe $(66,28 \%)$. Em seguida, veio o pH 8,0 (49,09\%), sendo que não houve diferença significativa entre os resultados obtidos para o $\mathrm{pH}$ $6,0(39,90 \%)$ e $9,0(37,41 \%)$. Estando todos estes valores de $\mathrm{pH}$ dentro da faixa de maior atividade específica destas enzimas (pH de 6,0 a 9,0 para o EEB e de 7,0 a 9,0 para a pancreatina), era de se esperar que não houvesse diferença entre os resultados de remoção de Phe. Entretanto, o menor valor obtido em pH 6,0 e 9,0 poderia ter ocorrido, provavelmente, pelo fato de que tanto o EEB quanto a pancreatina são constituídos de misturas de enzimas e outros interferentes da qualidade enzimática, minimizando as suas estabilidades nestes dois valores extremos de $\mathrm{pH}$. No caso do EEB, estes interferentes poderiam incluir açúcares solúveis, corantes, polissacarídeos, fibra. Como a pancreatina não consiste, apenas, de uma enzima purificada e sim de uma mistura de enzimas diversas (amilase, tripsina, lípase, ribonuclease e protease), a presença destes constituintes pode, provavelmente, interferir em sua qualidade enzimática.

\section{Temperatura}

Para avaliar o efeito da temperatura na remoção de Phe, foram comparados os hidrolisados 1, 2, 3 e 4 (35, 40, 50 e $70{ }^{\circ} \mathrm{C}$, respectivamente). Pode-se observar na Tabela 2 que a temperatura afetou o percentual de remoção, sendo que o melhor resultado foi obtido empregando-se a temperatura de $50{ }^{\circ} \mathrm{C}\left(66,28 \%\right.$ de remoção), seguido do uso de $35^{\circ} \mathrm{C}(61,53 \%$ de remoção). Por último, ficaram os hidrolisados preparados às temperaturas de $40{ }^{\circ} \mathrm{C}(57,49 \%)$ e $70{ }^{\circ} \mathrm{C}(56,93 \%)$, para os quais 
não houve diferença significativa. $O$ fato de que a remoção de Phe tenha sido maior a $50^{\circ} \mathrm{C}$ poderia ser explicado, pelo menos em parte, por ser esta a temperatura ótima da pancreatina. Por outro lado, o mesmo não ocorreu a $70{ }^{\circ} \mathrm{C}$, apesar de ser esta a temperatura ótima para o EEB. Neste caso, o que pode ter ocorrido é que, embora o emprego de temperaturas mais elevadas aumente o rendimento das reações enzimáticas, pode também provocar a inativação de enzimas, comprometendo o processo de hidrólise (FENNEMA, 1996).

Lopes et al. (2007), trabalhando com hidrolisados de leite, obtiveram, tal como no presente trabalho, maior remoção de Phe (98\%) à temperatura de $50^{\circ} \mathrm{C}$. Entretanto, neste estudo este valor somente foi comparado ao de $25^{\circ} \mathrm{C}(94 \%)$. Este resultado foi explicado pela maior exposição de Phe promovida por maior grau de hidrólise a $50^{\circ} \mathrm{C}$.

Da mesma forma, Santos (2005), ao avaliar o efeito da temperatura na remoção de Phe em hidrolisados proteicos de soro de leite obtidos com uma preparação proteolítica de P. candidum (E:S 10:100), relatou a obtenção de um menor teor de Phe ao usar a temperatura de $50{ }^{\circ} \mathrm{C}\left(71,2 \mathrm{mg}\right.$ Phe. $100 \mathrm{~g} \mathrm{~g}^{-1}$ de hidrolisado), quando comparado ao obtido a $30{ }^{\circ} \mathrm{C}$ (301,6 mg Phe.100 $\mathrm{g}^{-1}$ de hidrolisado).

\section{Tempo}

O efeito do tempo de ação das enzimas EEB e pancreatina sobre o percentual de remoção de Phe pode ser observado na Tabela 2, ao se comparar os hidrolisados 3, 5 e 6 . Nota-se que os melhores resultados foram obtidos, ao se aumentar o tempo de ação da pancreatina e, consequentemente, reduzir o de EEB, sendo os valores obtidos de 66,28\% (EEB 1 hora e 30 minutos + pancreatina 3 horas e 30 minutos), 42,26\% (EEB 2 horas e 30 minutos + pancreatina 2 horas e 30 minutos) e $38,76 \%$ (EEB 3 horas e 30 minutos + pancreatina 1 hora e 30 minutos).

Não foram encontrados na literatura trabalhos que estudem o efeito do tempo de ação enzimática sobre a remoção de Phe de hidrolisados proteicos de farinha de trigo ou de outra fonte proteica.

\section{Conclusões}

A associação de duas proteases para a hidrólise das proteínas da farinha de trigo e o emprego do CA como meio adsorvente mostraram-se eficazes na obtenção de hidrolisados proteicos de farinha de trigo, com teor reduzido de Phe, tendo atingido $522,44 \mathrm{mg}$ Phe.100 g-1 , o que corresponde a 66,28\% de remoção. Os três parâmetros estudados afetaram a remoção de Phe, sendo a melhor combinação para a remoção de Phe a associação EEB (E:S 10:100, 1 hora e 30 minutos), com a pancreatina (E:S $4: 100,3$ horas e 30 minutos), no $\mathrm{pH} 7,0$ à temperatura de $50^{\circ} \mathrm{C}$. Embora os conteúdos de Phe ainda estejam elevados, estes podem ser reduzidos até o limite da legislação $\left(100 \mathrm{mg}^{1} 100 \mathrm{~g} \mathrm{~g}^{-1}\right)$ pela combinação com o resíduo (amido) que foi separado no início da extração proteica.

\section{Agradecimentos}

Os autores agradecem o apoio financeiro da CAPES, CNPq e FAPEMIG.

\section{Referências bibliográficas}

AB ENZYMES. Corolase PP: description and specification. Review Nutrition, n. 2, p. 2, 2001.

ASSOCIATION OF OFFICIAL AGRICULTURAL CHEMISTS AOAC. Official methods of analysis of AOAC International. 16 ed. Arlington, 1995.

BIZZOTTO, C. S. et al. Hidrolisados protéicos de arroz com baixo teor de fenilalanina, obtidos pela ação da corolase PP e uso do carvão ativado. Ciência e Agrotecnologia, v. 30, n. 2, p. 308-316, 2006 a.

BIZZOTTO, C. S. et al. Uso da pancreatina e do carvão ativado no preparo de hidrolisados protéicos de arroz com baixo teor de fenilalanina. Revista Tecno-Lógica, v. 10, n. 1, p. 9-30, 2006 b.

BRANDTS, J. F.; KAPLAN, L. J. Derivate spectroscopy applied to tyrosiyl chromophores. Studies on ribonuclease, lima bean inhibitors, insulin, and pancreatic trypsin inhibitor. Biochemical, v. 12, n. 10, p. 2011-2024, 1973.

BRASIL. Ministério da Saúde. Portaria n. 354, de 18 de julho de 1996. Norma Técnica referente a farinha de trigo. Diário Oficial [da] República Federativa do Brasil, Poder Executivo, Brasília, DF, 22 de julho de 1996, Seção 1, p. 13557-13558.

BRASIL. Ministério da Saúde. Portaria n. 847, de 31 de outubro de 2002. Aprova o protocolo clínico e diretrizes terapêuticas - fenilcetonúria fórmulas de aminoácidos isenta de fenilalanina. Diário Oficial [da] República Federativa do Brasil, Poder Executivo, Brasília, DF, 04 de novembro de 2002, Seção 1, p. 83.

BRASIL. Ministério da Agricultura, Pecuária e Abastecimento. Instrução Normativa n. 8, de 2 de junho de 2005. Regulamento técnico de identidade e qualidade da farinha de trigo. Diário Oficial [da] República Federativa do Brasil, Poder Executivo, Brasília, DF, 3 de junho de 2005, Seção 1, p. 91.

CAHILL, J. E.; PADERA, F. G. Derivate analysis of uv/visible spectra. American Laboratory, v. 12, n. 4, p. 101-112, 1980.

CAPOBIANGO, M. et al. Optimization of enzyme assisted processes for extracting and hydrolysing corn proteins aiming phenylalanine removal. International Journal of Food and Engineering, v. 3, n. 6, p. 1-19, 2007.

CAPOBIANGO, M. et al. Ação da corolase pp e uso do carvão ativado na obtenção de hidrolisados protéicos de fubá de milho com baixo teor de fenilalanina. Revista Brasileira de Nutrição Clínica, v. 21, n. 4, p. 259-266, 2006.

COGAN, U.; MOSHE, M.; MOKADY, M. Debittering and nutritional upgrading of enzymic casein hydrolysates. Journal of the Science of Food and Agriculture, v. 32, n. 2, p. 459-466, 1981.

DELVIVO, F. M. et al. Effect of adsorption medium, hydrolytic parameters and ultrafiltration on the phenylalanine removal from pancreatic whey hydrolysates. American Journal of Food Technology, v. 1, n. 2, p. 94-104, 2006.

FENNEMA, O. R. Food chemistry. 3 ed. New York: Marcel Dekker, 1996. $1067 \mathrm{p}$.

ICHIKAWA, T.; TERADA, H. Second derivative spectrophotometry as an effective tool for examining phenylalanine residues in proteins. Biochimica \& Biophysica Acta, v. 494, n. 1, p. 267-270, 1977.

ICHIKAWA, T.; TERADA, H. Estimation of state and amount of phenylalanine residues in proteins by second derivative spectrophotometry. Biochimica \& Biophysica Acta, v. 580, n. 1, p. 120-128, 1979.

ICHIKAWA, T.; TERADA, H. Determination of phenylalanine, tryptophan and tyrosine in a mixture of amino acids by second 
derivative spectrophotometry. Chemical \& Pharmaceutical Bulletin, v. 29, n. 2, p. 438-444, 1981a.

ICHIKAWA, T.; TERADA, H. Effect of dodecyl sulfate on the spectral properties of phenylalanil residues in serum albumin detected by second derivative spectrophotometry. Biochimica \& Biophysica Acta, v. 671, n. 1, p. 33-37, 1981b.

LOPES, D. C. F. et al. Phenylalanine removal from whey hydrolysates. Journal of Food Technology, v. 5, n. 2, p. 191-197, 2007.

LOPES, D. C. F.; DELVIVO, F. M.; SILVESTRE, M. P. C. Use of activated carbon for removing phenylalanine from skim milk powder. Food Science and Technology, v. 38, n. 5, p. 447-453, 2005.

LOPEZ-BAJONERO, L. J. et al. Enzymatic production of a lowphenylalanine product from skim milk powder and caseinate. Journal of Food Science, v. 56, n. 4, p. 938-942, 1991.

MACRITCHIE, F.; LAFIANDRA, D. Structure-function relationships of wheat proteins. In: DAMODARAN, S.; PARAFF, A. (ed.). Food Proteins and their applications. New York: Marcel Dekker, 1997. p. 293-322. (cap. 10)

DE MARCO, L. M. et al. Uso do carvão ativado para remoção de fenilalanina de hidrolisados protéicos, obtidos pela ação da papaína imobilizada. Brazilian Journal of Food Technology, v. 8, n. 3, p. 210-219, 2005.

MATSUSHIMA, A.; INOUE, Y.; SHIBATA, K. Derivative absortion spectrophotometry of native proteins. Analytical Biochemistry, v. 65 , n. 1 , p. $362-368,1975$.

MIRA, N. V. M.; MARQUEZ, U. M. L. Importância do diagnóstico e tratamento da fenilcetonúria. Revista de Saúde Pública, v. 34, n. 1, p. 86-96, 2000.

MONTEIRO, L. T. B.; CÂNDIDO, L. M. B. Fenilcetonúria no Brasil: evolução e casos. Revista de Nutrição, v. 19, n. 3, p. 381-387, 2006.

MORAIS, H. A. et al. Caracterização do perfil peptídico e de aminoácidos em hidrolisados de caseína. Archivos Latinoamericanos de Nutrición, v. 52, n. 1, p. 77-83, 2002.

MOSZCZYNSKI, P.; IDIZIAK, J. Preparation of enzymatic hydrolysates of casein depleted in phenylalanine. Application of Biochemical Microbiology, v. 29, n. 3, p. 302-306, 1993.

NÚCLEO DE AÇÕES E PESQUISA EM APOIO DIAGNÓSTICO NUPAD. Comunicação pessoal. Belo Horizonte, 2002.
O'HAVER, T. C. Potencial clinical applications of derivative and wavelength.-modulation spectrometry. Clinical Chemistry, v. 25, n. 9, p. 1548-1553, 1979.

OUTINEN, M. T. et al. Method for removing phenylalanine from proteinaceous compositions, a product so obtained and use thereof. US n. PI 5547687, 20 aug. 1996.

PIMENTEL-GOMES, F. Curso de estatística experimental. 14 ed. Piracicaba: Nobel, 2000. 477 p.

SANTOS, R C. Obtenção de proteases de Penicilium candidum e seu emprego no preparo de hidrolisados protéicos de soro de leite com baixo teor de fenilalanina. Belo Horizonte, 2005. 99 p. Dissertação (Mestrado em Ciência de Alimentos) - Universidade Federal de Minas Gerais - UFMG.

SHIMAMURA, S. et al. Peptide mixture and products thereof. US n. PI 5952193, 14 sept. 1999.

SILVA, V. D. M. et al. Emprego da pancreatina imobilizada no preparo de hidrolisados de soro de leite com teor reduzido de fenilalanina. Alimentação e Nutrição, v. 16, n. 1, p. 21-31, 2005.

SILVESTRE, M. P. C.; DAUPHIN, D.; HAMON, M. Application of UV absorbance and second-derivative spectrophotometry for analysing casein hydrolysates. Analytica Chimica Acta, v. 82, n. 3, p. 603-612, 1993.

SOARES, R. D. L. et al. Preparation of enzymatic skim milk hydrolysates with low phenylalanine content. Acta Farmacéutica Bonaerense, v. 25 , n. 3, p. 325-332, 2006.

SOARES, R. D. L. et al. Emprego do carvão ativado para a remoção de fenilalanina de leite em pó. Boletim do Centro de Pesquisa e Processamento de Alimentos, v. 22, n. 1, p. 65-84, 2004.

TREMACOLDI, C. R.; CARMONA, E. C. Production of extracellular alkaline proteases by Aspergillus clavatus. World Journal of Microbiology and Biotechnology, v. 21, n. 2, p. 169-172, 2005.

VASCONCELLOS, A. M. H. et al. Adsorption chromatography of phenylalanine. Biotechnology and Bioengineering, v. 33, n. 10, p. 1324-1329, 1989.

VIEIRA, C. R. et al. Elaboração de hidrolisados protéicos de farinha de arroz destinados a dietoterapia de pacientes com fenilcetonúria. Revista Brasileira de Nutrição Clínica, v. 23, n. 2, p. 83-90, 2008. 